\title{
Assessment of the Mineral Composition of Heaving Soils Using Geotechnical Properties
}

\author{
Armand Augustin Fondjo ${ }^{*}$, Elizabeth Theron \\ Department of Civil Engineering, Central University of Technology, Free State, 20 President Street, Bloemfontein, South Africa
}

Received April 2, 2020; Revised May 21, 2020; Accepted June 4, 2020

Copyright $\odot 2020$ by authors, all rights reserved. Authors agree that this article remains permanently open access under the terms of the Creative Commons Attribution License 4.0 International License

\begin{abstract}
The behaviour of heaving soils is generally governed by the matric suction. Nonetheless, the mineralogical characteristics influence the geotechnical behaviour. X-ray diffraction is a common technique used to determine the mineral composition. This equipment is costly and the process time-consuming. The objective of this research is to develop predictive mathematical models to determine the predominant minerals in heaving soils. Soil samples are collected from identified areas across Free State province by digging at $50 \mathrm{~cm}$ depth from the ground surface. Geotechnical lab studies such as particle size distribution, Atterberg limits, specific gravity, free swell ratio, free swell index, linear shrinkage, and X-ray diffraction are performed to evaluate soil properties. A stepwise analysis is conducted to determine the response of each type of mineral to soil properties, and select the best subsets. Moreover, the influence of soil minerals on soil properties is achieved by investigating the correlation between the relevant soil properties and each mineral. Multivariate regression is performed utilizing MINITAB 18 program to develop mathematical predictive models. These equations are assessed base on correlation coefficient, probability value (P-value), and standard residual pattern analysis. The predominant minerals can be assessed with acceptable accuracy utilizing the proposed semi-empirical models.
\end{abstract}

Keywords Soil Mineralogy, Regression Analysis, Geotechnical Properties, X-ray Diffraction

\section{Introduction}

Smectite mineral is mainly located in a semi-arid climate where evapotranspiration exceeds rainfall during a significant period of the year. The absence of leaching in these areas leads to the formation of the smectite [1]. The determination of the soil mineralogy is generally conducted using the X-ray diffraction technique. However, the equipment is expensive, and the process time-consuming. The objective of this investigation is to develop a mathematical predictive model that can be used to evaluate the mineral composition of heaving soils. Methods to investigate the mineral composition have been well reported in the literature. Reference [2] proposed the free swell ratio method that is utilized to determine the swelling capacity and the dominant clay minerals (smectite, kaolinite). However, this method cannot be used to determine the mineral percentage in the soil. Another research work conducted by [3] revealed that the specific gravity is an important soil parameter related to the mineralogy and chemical composition of the soil. Reference [4] examined the statistical variability of the correlations between liquid limit and plasticity index of kaolinite and smectite, specimens of smectite and kaolinite that have been plotted and compared to one another. The results show that the relationship between the Atterberg limits is influenced by the clay mineralogy. Consequently, the plasticity index and the liquid limit can be utilized as independent variables for the prediction of the clay mineral. Reference [5] reported the effect of the mineralogy on geotechnical parameters of clayey soils in the upper east of Ankara Turkey. Reference [5] correlated the geotechnical properties and mineralogical characteristics using the results obtained from geotechnical lab studies. The results demonstrate an immediate correlation between the plasticity index and the smectite content just as a direct correlation between the plasticity index and the smectite-kaolinite ratio. Moreover, the mineralogical characteristics significantly influence the geotechnical behaviour of heaving soils. Therefore, the geotechnical properties can be utilized to approximate the mineral composition of heaving soils. These findings are in line with the outcomes of the investigation conducted by [4]. Nevertheless, the study did not consider the non-clay mineral. The literature survey revealed a significant influence of the mineral composition on geotechnical properties. 


\section{Materials and Methods}

Soil samples were collected by digging out from the site at $50 \mathrm{~cm}$ from the ground surface across Free State province, South Africa. Petrusburg soils (PTS-A; PTS-B; PTS-C); Bloemfontein soils (BLS-A; BLS-B; BLS-C); Winburg soils (WBS-A; WBS-B; WBS-C); Welkom soils (WKS-A; WKS-B; WKS-C); Bethlehem soils (BTS-A; BTS-B; BTS-C). The GPS coordinates are (PTS-A: $29^{\circ} 07^{\prime} 09.8^{\prime \prime S} ; \quad 25^{\circ} 25^{\prime} 18.9^{\prime \prime} \mathrm{E}$ ); (PTS-B: $29^{\circ} 06^{\prime} 42.1^{\prime \prime S}$; $\left.25^{\circ} 24^{\prime} 39.1 " \mathrm{E}\right)$; (PTS-C: $29^{\circ} 07^{\prime} 02.80^{\prime \prime} \mathrm{S} ; 25^{\circ} 24^{\prime} 28.20^{\prime \prime} \mathrm{E}$ ); (BLS-A: 29 $11^{\prime} 49.53 " \mathrm{~S} ; \quad 26^{\circ} 12^{\prime}$ 52.55"E); (BLS-B: $29^{\circ} 08^{\prime} 04.40 " \mathrm{~S}$; $\left.26^{\circ} 15^{\prime} 58.10^{\prime \prime} \mathrm{E}\right)$; (BLS-C: $29^{\circ} 06^{\prime} 48.20^{\prime \prime} \mathrm{S}$; $26^{\circ} 10^{\prime} 56.70^{\prime \prime} \mathrm{E}$ ); (WBS-A: $28^{\circ} 30^{\prime} 43.5^{\prime \prime} \mathrm{S} ; 27^{\circ} 00^{\prime} 12.8^{\prime \prime} \mathrm{E}$ ); (WBS-B: $28^{\circ} 30^{\prime} \quad 59.8^{\prime \prime} \mathrm{S} ; \quad 27^{\circ} 00^{\prime} 58.0^{\prime \prime} \mathrm{E}$ ); (WBS-C: $28^{\circ} 31^{\prime} 08.00^{\prime \prime S}$; $27^{\circ} 00^{\prime} 22.00^{\prime \prime E}$ ); (WKS-A: $27^{\circ} 57^{\prime} 51.8^{\prime \prime}$; $26^{\circ} 45^{\prime} 36.9^{\prime \prime E}$ ); (WKS-B: $28^{\circ} 00^{\prime} 12.10^{\prime \prime} \mathrm{S}$; $26^{\circ} 43^{\prime} 52.30^{\prime \prime} \mathrm{E}$ ); (WKS-C: $\left.27^{\circ} 58^{\prime} 15.10^{\prime \prime} \mathrm{S} ; 26^{\circ} 43^{\prime} 05.00^{\prime \prime} \mathrm{E}\right)$ (BTS-A: $28^{\circ} 13^{\prime}$ 23.4"S; $\left.28^{\circ} 19^{\prime} 23.0^{\prime \prime} \mathrm{E}\right) ; \quad$ (BTS-B: $28^{\circ} 13^{\prime} \quad 38.70^{\prime \prime} \mathrm{S}$; $\left.28^{\circ} 18^{\prime} 54.50^{\prime \prime} \mathrm{E}\right)$; (BTS-C: $\left.28^{\circ} 14^{\prime} 11.10^{\prime \prime} \mathrm{S} ; 28^{\circ} 19^{\prime} 05.50^{\prime \prime} \mathrm{E}\right)$. To assess the physical and hydro-mechanical properties of soils, laid down protocols and standards found in the literature were utilized: Sieve analysis [6]; Hydrometer analysis [7]; Atterberg limits [8]; Free swell index [9]; Specific gravity [10]; Free swell ratio [2], X-ray diffraction technique [11].

\subsection{Multivariate Regression Analysis}

Regression analysis is an extensively used method to analyze multifactor data. This method is easy to formulate equations that link the dependent variables and independent variables. The regression analysis is performed using MINITAB 18 program. The predominant minerals: smectite, quartz, k-feldspar, and plagioclase are the dependent variables. The independent variables are classified as follows: geotechnical index properties, and expansive soil indexes. Reference [12] stated that the predictive multi-linear model takes the form of equation (1), the intercept, denoted by $\left(\beta_{0}\right)$, the regression coefficient, denoted by $\left(\beta_{\mathrm{i}}\right)$, the number of relevant soil parameters, denoted by $(\mathrm{n})$, and the random error, denoted by $(\varepsilon)$.

$$
\mathrm{Y}=+\beta_{\mathrm{o}}+\sum_{\mathrm{i}=1}^{\mathrm{n}}\left(\beta_{\mathrm{i}} \mathrm{X}_{\mathrm{i}}+\varepsilon\right)
$$

\section{Results and Discussion}

\subsection{Material Properties}

The material properties of soil samples used in this study is summarized in Table 1. PTS, BLS, WBS, WKS, BTS are fine-grained soils, more than $50 \%$ passing the No 200 $(0,075 \mathrm{~mm})$. The liquid limit values of PTS-B, PTS-C, BLS, WBS, and WKS are $>50 \%$, these soils exhibit high plasticity, and denoted by $(\mathrm{CH})$. However, the liquid limit values of PTS-A and BTS are $<50 \%$, these soils portray low plasticity, and denoted by (CL).

Table 1. Material properties

\begin{tabular}{|c|c|c|c|c|c|c|c|c|c|c|}
\hline \multicolumn{2}{|c|}{$\begin{array}{c}\text { Soil } \\
\text { designation }\end{array}$} & \multirow{2}{*}{$\begin{array}{c}\begin{array}{c}\text { Liquid limit } \\
\text { (LL) } \\
\%\end{array} \\
48,91\end{array}$} & \multirow{2}{*}{$\begin{array}{c}\text { Plasticity index } \\
\text { (PI) } \\
\%\end{array}$} & \multirow{2}{*}{$\begin{array}{c}\text { Linear } \\
\text { Shrinkage } \\
\text { (LS) } \\
\% \\
13,51\end{array}$} & \multirow{2}{*}{$\begin{array}{c}\begin{array}{c}\text { Clay } \\
\%\end{array} \\
23,14\end{array}$} & \multirow{2}{*}{$\begin{array}{c}\begin{array}{c}\text { Fine } \\
\%\end{array} \\
52,19\end{array}$} & \multirow{2}{*}{$\begin{array}{c}\begin{array}{c}\text { Sand } \\
\%\end{array} \\
30,75\end{array}$} & \multirow{2}{*}{$\begin{array}{c}\text { Gravel } \\
\%\end{array}$} & \multirow{2}{*}{$\begin{array}{c}\begin{array}{c}\text { Specific } \\
\text { gravity } \\
\text { (Gs) }\end{array} \\
2,6\end{array}$} & \multirow{2}{*}{$\begin{array}{c}\text { USCS } \\
\text { CL }\end{array}$} \\
\hline \multirow{3}{*}{ PTS } & PTS-A & & & & & & & & & \\
\hline & PTS-B & 51,08 & 32,46 & 12,931 & 26,56 & 54,51 & 32,45 & 12,16 & 2,63 & $\mathrm{CH}$ \\
\hline & PTS-C & 54,78 & 34,81 & 12,06 & 29,85 & 58,45 & 31,97 & 9,45 & 2,66 & $\mathrm{CH}$ \\
\hline \multirow{3}{*}{ BLS } & BLS-A & 58,98 & 36,82 & 9,28 & 30,4 & 59,51 & 29,39 & 10.09 & 2,64 & $\mathrm{CH}$ \\
\hline & BLS-B & 61,27 & 38,25 & 8,93 & 32,2 & 61,82 & 29,49 & 8.38 & 2,68 & $\mathrm{CH}$ \\
\hline & BLS-C & 64,6 & 40,33 & 8,47 & 35,07 & 65,18 & 30,48 & 4.32 & 2,71 & $\mathrm{CH}$ \\
\hline \multirow{3}{*}{ WBS } & WBS-A & 63,78 & 42,48 & 7,69 & 34,03 & 67,52 & 26,8 & 4.85 & 2,73 & $\mathrm{CH}$ \\
\hline & WBS-B & 66,22 & 44,10 & 7,41 & 36,5 & 70,1 & 27,2 & 2.45 & 2,76 & $\mathrm{CH}$ \\
\hline & WBS-C & 70,64 & 47,04 & 6,97 & 39,73 & 74,78 & 23,98 & 1.21 & 2,78 & $\mathrm{CH}$ \\
\hline \multirow{3}{*}{ WKS } & WKS-A & 69,45 & 49,87 & 6,12 & 40 & 73 & 23,5 & 2.56 & 2,73 & $\mathrm{CH}$ \\
\hline & WKS-B & 74,31 & 53,36 & 5,72 & 48,31 & 78,11 & 18,71 & 1.98 & 2,78 & $\mathrm{CH}$ \\
\hline & WKS-C & 78,94 & 56,68 & 5,38 & 55,25 & 82,98 & 15,92 & 1.10 & 2,83 & $\mathrm{CH}$ \\
\hline \multirow{3}{*}{ BTS } & BTS-A & 40,29 & 19,23 & 16,67 & 12,31 & 41,24 & 44,66 & 13,85 & 2,55 & $\mathrm{CL}$ \\
\hline & BTS-B & 43,59 & 20,8 & 15,41 & 16,18 & 44,61 & 45,31 & 9,96 & 2,59 & CL \\
\hline & BTS-C & 48,37 & 23,09 & 13,89 & 20 & 49,5 & 44 & 6,48 & 2,63 & CL \\
\hline
\end{tabular}


Table 2. Swelling potential assessment results

\begin{tabular}{|c|c|c|c|c|c|c|c|}
\hline \multicolumn{2}{|c|}{$\begin{array}{c}\text { Soil } \\
\text { designation }\end{array}$} & $\begin{array}{c}\text { LL } \\
(\%)\end{array}$ & $\begin{array}{c}\text { Swelling potential, } \\
\text { LL classification. } \\
{[13]}\end{array}$ & FSR & $\begin{array}{c}\text { Swelling potential, } \\
\text { FSR classification. } \\
{[2]}\end{array}$ & $\begin{array}{c}\text { FSI } \\
(\%)\end{array}$ & $\begin{array}{c}\text { Swelling potential, } \\
\text { FSI classification. } \\
{[9]}\end{array}$ \\
\hline \multirow{4}{*}{ PTS } & PTS-A & 48,91 & Medium & 1,42 & Low & 50,71 & Moderate \\
\cline { 2 - 8 } & PTS-B & 51,08 & High & 1,49 & Low & 53,21 & Moderate \\
\cline { 2 - 8 } & PTS-C & 54,78 & High & 1,6 & Moderate & 57,14 & Moderate \\
\hline \multirow{4}{*}{ BLS } & BLS-A & 58,98 & High & 1,64 & Moderate & 64,31 & Moderate \\
\cline { 2 - 8 } & BLS-B & 61,27 & High & 1,7 & Moderate & 66,66 & Moderate \\
\cline { 2 - 8 } & BLS-C & 64,6 & High & 1,79 & Moderate & 70,19 & Moderate \\
\hline \multirow{5}{*}{ WBS } & WBS-A & 63,78 & High & 1,73 & Moderate & 81,37 & Moderate \\
\cline { 2 - 8 } & WBS-B & 66,22 & High & 1,8 & Moderate & 84,66 & Moderate \\
\cline { 2 - 9 } & WBS-C & 70,64 & Very high & 1,92 & Moderate & 90,3 & Moderate \\
\hline \multirow{3}{*}{ WKS } & WKS-A & 69,45 & High & 2,2 & High swelling & 116,6 & High swelling \\
\cline { 2 - 8 } & WKS-B & 74,31 & Very high & 2,35 & High swelling & 124,6 & High swelling \\
\cline { 2 - 8 } & WKS-C & 78,94 & Very high & 2,5 & High swelling & 132,6 & High swelling \\
\hline \multirow{3}{*}{ BTS } & BTS-A & 40,29 & Medium & 1,17 & Low & 35,81 & Moderate \\
\cline { 2 - 8 } & BTS-B & 43,59 & Medium & 1,26 & Low & 38,56 & Moderate \\
\cline { 2 - 8 } & BTS-C & 48,37 & Medium & 1,4 & Low & 42,85 & Moderate \\
\hline
\end{tabular}

\subsection{Swelling Property Assessment}

The investigation of the swelling potential performed according to heaving soils classification utilizing the liquid limit (LL) as proposed by [13], the free swell ratio (FSR) as proposed by [2] and the free swell index (FSI) following [9]. The summary of the swelling properties is presented in Table 2. The results have revealed that all-samples exhibit a swelling behaviour. Additionally, some similarities and differences in classification were observed. According to the classification [2] and [9], WKS exhibits a high swelling potential whereas BLS and WBS exhibit a moderate swelling potential at various levels. However, [2] classified BTS, PTS-A, PTS-B as low swelling soils while [9] classified PTS as BTS as moderate swelling. Moreover, it can be observed that the [13] classification approach overestimates the swelling potential compared to [2] and [9] classifications. These discrepancies can be justified by the differences in classification methods. Reference [13] classification utilizing the liquid limit did not evaluate efficiently the swelling potential because the liquid limit represents the boundary between the plastic state and liquid state. The similarities observed between [2] and [9] can be explained by the fact that the procedure techniques are very similar. FSR and FSI give better results compared to the classification utilizing the liquid limit.

\subsection{X-ray Diffraction Analysis}

Specimens were analyzed for their major mineral content utilizing the X-ray diffraction technique [11]. Specimen holders were front-loaded. After, the sample holder was kept at $45^{\circ}$ with the horizontal to check the correctness of the loading condition. The loading process was conducted until the planes of the sample and holder were uniformed. Moreover, the tray containing the sample holder was placed in the multi-purposes diffractometer as shown in Figure 1. The process is computer-assisted using the program XRD Diffrac Plus Commander. The process continues until the end of the test. The specimens were identified utilizing abbreviations as BTS, PTS, BLS, WBS, WKS. The file parameter was created using XRD Wizard. After performing the scan, the results were saved automatically in the raw file. The results in Table 3 revealed that smectite is the predominant clay mineral in these soils, a very small amount of illite and trace of illite were found. Besides, silica and a group of feldspar minerals (plagioclase, k-feldspar) are the predominant non-clay mineral. A very small quantity of calcite and trace of calcite were found. The significant content in smectite can explain the swelling behaviour of these soils. 


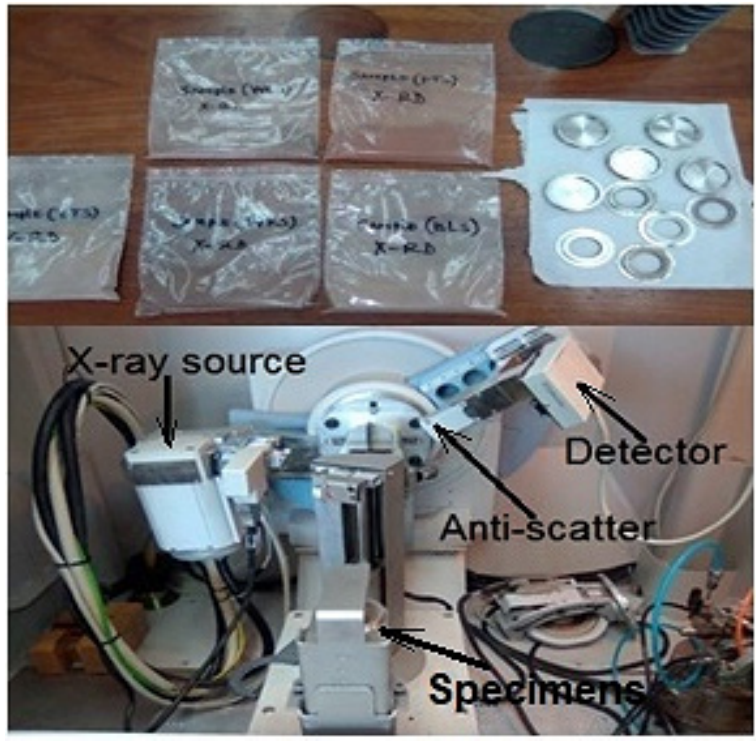

Figure 1. Sample preparation by front loading and multipurpose diffractometer used for the XRD test

Table 3. X-ray diffraction results

\begin{tabular}{|c|c|c|c|c|c|c|c|}
\hline \multirow{2}{*}{\multicolumn{2}{|c|}{$\begin{array}{c}\text { Soil } \\
\text { designation }\end{array}$}} & \multirow{3}{*}{$\begin{array}{c}\begin{array}{c}\text { Smectite } \\
(\%)\end{array} \\
49,64\end{array}$} & \multirow{3}{*}{$\begin{array}{c}\begin{array}{c}\text { Silica } \\
(\%)\end{array} \\
12,58\end{array}$} & \multicolumn{2}{|c|}{ Group of feldspar minerals } & \multirow{3}{*}{$\begin{array}{r}\text { Illite } \\
(\%)\end{array}$} & \multirow{3}{*}{$\begin{array}{c}\begin{array}{c}\text { Calcite } \\
(\%)\end{array} \\
2,31\end{array}$} \\
\hline & & & & \multirow{2}{*}{$\begin{array}{c}\begin{array}{c}\text { K-feldspar } \\
(\%)\end{array} \\
27,05\end{array}$} & \multirow{2}{*}{$\begin{array}{c}\begin{array}{c}\text { Plagioclase } \\
(\%)\end{array} \\
4,67\end{array}$} & & \\
\hline \multirow{3}{*}{ PTS } & PTS-A & & & & & & \\
\hline & PTS-B & 51,55 & 13,14 & 25,12 & 5,21 & 1,31 & 3,67 \\
\hline & PTS-C & 55,61 & 13,1 & 24,96 & 6,33 & trace & trace \\
\hline \multirow{3}{*}{ BLS } & BLS-A & 56,83 & 12,47 & 23,51 & 3,29 & 1,89 & 2,01 \\
\hline & BLS-B & 58 & 14 & 24,88 & 3,12 & trace & trace \\
\hline & BLS-C & 61,15 & 11,93 & 19,01 & 2,63 & 3,3 & 1,98 \\
\hline \multirow{3}{*}{ WBS } & WBS-A & 58,22 & 25,08 & 10,42 & 2,45 & 2,02 & 1,81 \\
\hline & WBS-B & 59,41 & 27,7 & 9,99 & 2,9 & trace & trace \\
\hline & WBS-C & 63,37 & 20,34 & 10,71 & 1,8 & 2,43 & 1,35 \\
\hline \multirow{3}{*}{ WKS } & WKS-A & 67,05 & 19,98 & 10,66 & 2,31 & trace & trace \\
\hline & WKS-B & 71,74 & 13,4 & 9,91 & 1,85 & 1,89 & 1,22 \\
\hline & WKS-C & 76,21 & 11,69 & 8,57 & 1,25 & 1,14 & 1,18 \\
\hline \multirow{3}{*}{ BTS } & BTS-A & 31,67 & 31,39 & 21,22 & 8,15 & 3,36 & 4,21 \\
\hline & BTS-B & 34,26 & 30,75 & 20,32 & 7,04 & 2,11 & 5,52 \\
\hline & BTS-C & 38,02 & 38,98 & 17,23 & 5,77 & trace & trace \\
\hline
\end{tabular}

\subsection{Analysis of the Correlation between Smectite and Soil Properties}

The smectite content response to the soil properties is shown in Table 4. The highlighted row exhibits the best subsets to correlate the smectite content. Therefore, the analysis of the correlations between the smectite content and plasticity index (PI), free swell ratio (FSR), specific gravity (Gs), and free swell index (FSI) is performed.

Figures $2 \& 3$ are the three-dimensional representation of the relationship between the smectite content and the following soil parameters: plasticity index, free swell ratio, specific gravity, and free swell index. Colour patterns are used to display the smectite content. Figure 2 shows a surface plot of smectite, plasticity index, and free swell ratio. The smectite content increases with the increase of the plasticity index and displays a strong correlation, with a determination coefficient of $\mathrm{R}^{2}=96,63 \%$. Also, the smectite content increases as the free swell ratio increases and exhibits a linear correlation, with a determination coefficient of $\mathrm{R}^{2}=81,06 \%$. This can be explained by the fact that the augmentation of smectite increases the plasticity index. Reference [13] reported the impact of the plasticity index on swell potential using the liquid limit to classify the swelling potential. Besides, these results are in line with the study conducted by [4] on the relationship between the plasticity index and the liquid limit of smectite and kaolinite which revealed that the Atterberg limits are also influenced by the clay mineralogy. Figure 3 shows a surface plot of smectite, specific gravity, and free swell index. The smectite content increases as the specific gravity increases and exhibits a good correlation, with a determination coefficient of $\mathrm{R}^{2}=81,06 \%$. Moreover, the smectite content increases as the free swell index increases and 
exhibits a good determination coefficient of $\mathrm{R}^{2}=81,06 \%$. This can be justified by the fact that the free swell ratio and the free swell index increases when the smectite content increases in heaving soils. Reference [2] pointed out the influence of smectite on the free swell ratio by using the free swell ratio as a parameter to determine the swelling potential.

Table 4. Smectite response

\begin{tabular}{|c|c|c|c|c|c|c|c|c|c|c|}
\hline Variables & R-Sq & R-Sq (adj) & R-Sq (pred) & Mallows Cp & PI, \% & FSR & Gs & FSI, \% & Gravel, \% & Sand, \% \\
\hline 1 & 96,6 & 96,4 & 95,6 & 378,0 & $\mathrm{x}$ & & & & & \\
\hline 1 & 95,8 & 95,5 & 94,8 & 467,6 & & & & & & $\mathrm{x}$ \\
\hline 2 & 97,8 & 97,4 & 96,8 & 248,4 & $\mathrm{x}$ & & & $\mathrm{x}$ & & \\
\hline 2 & 97,6 & 97,2 & 96,5 & 264,4 & $\mathrm{x}$ & & & & $\mathrm{x}$ & \\
\hline 3 & 99,1 & 98,9 & 98,5 & 96,9 & $\mathrm{x}$ & $\mathrm{x}$ & & $\mathrm{x}$ & & \\
\hline 3 & 98,7 & 98,3 & 97,1 & 147,1 & & $\mathrm{x}$ & & $\mathrm{x}$ & & $\mathrm{x}$ \\
\hline 4 & 99,9 & 99,8 & 99,7 & 8,1 & $\mathbf{x}$ & $\mathbf{x}$ & $\mathbf{x}$ & $\mathbf{x}$ & & \\
\hline 4 & 99,8 & 99,8 & 99,6 & 13,6 & $\mathrm{x}$ & $\mathrm{x}$ & & $\mathrm{x}$ & $\mathrm{x}$ & \\
\hline 5 & 99,9 & 99,9 & 99,8 & 5,5 & $\mathrm{x}$ & $\mathrm{x}$ & $\mathrm{x}$ & $\mathrm{x}$ & $\mathrm{x}$ & \\
\hline 5 & 99,9 & 99,9 & 99,8 & 7,1 & $\mathrm{x}$ & $\mathrm{x}$ & $\mathrm{x}$ & $\mathrm{x}$ & & $\mathrm{x}$ \\
\hline 6 & 99,9 & 99,9 & 99,8 & 7,0 & $\mathrm{x}$ & $\mathrm{x}$ & $\mathrm{x}$ & $\mathrm{x}$ & $\mathrm{x}$ & $\mathrm{x}$ \\
\hline
\end{tabular}

Smectite, \%
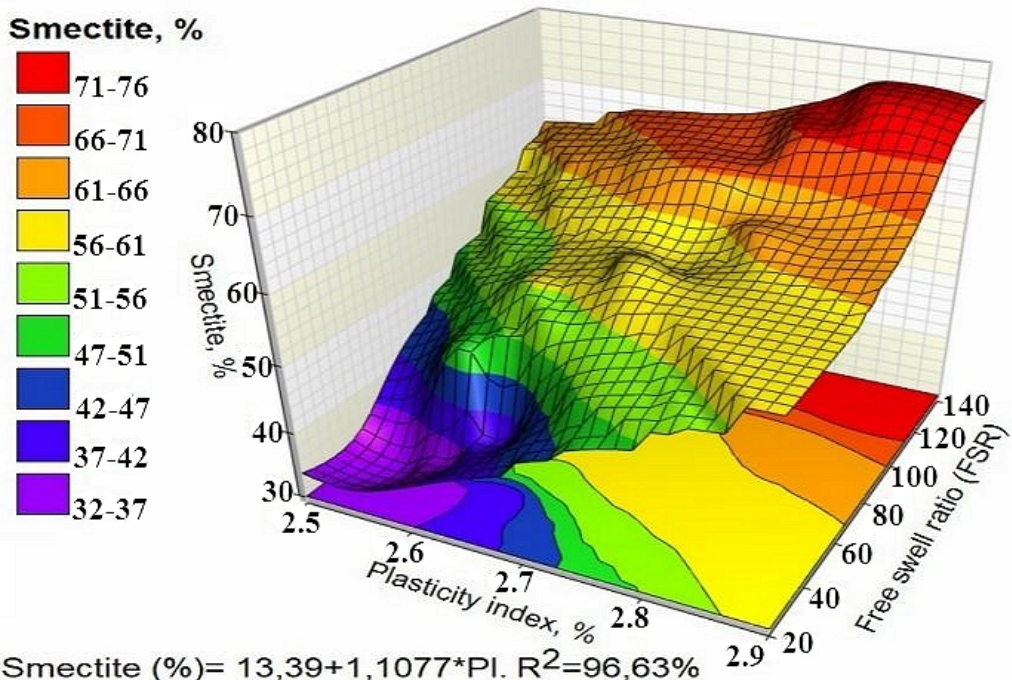

Smectite $(\%)=13,39+1,1077^{\star} \mathrm{PI} . \mathrm{R}^{2}=96,63 \%$

Smectite $(\%)=0,87+31,56^{\star} F S R R^{2}=88,51 \%$

Figure 2. Surface plot of smectite vs plasticity index. Free swell ratio
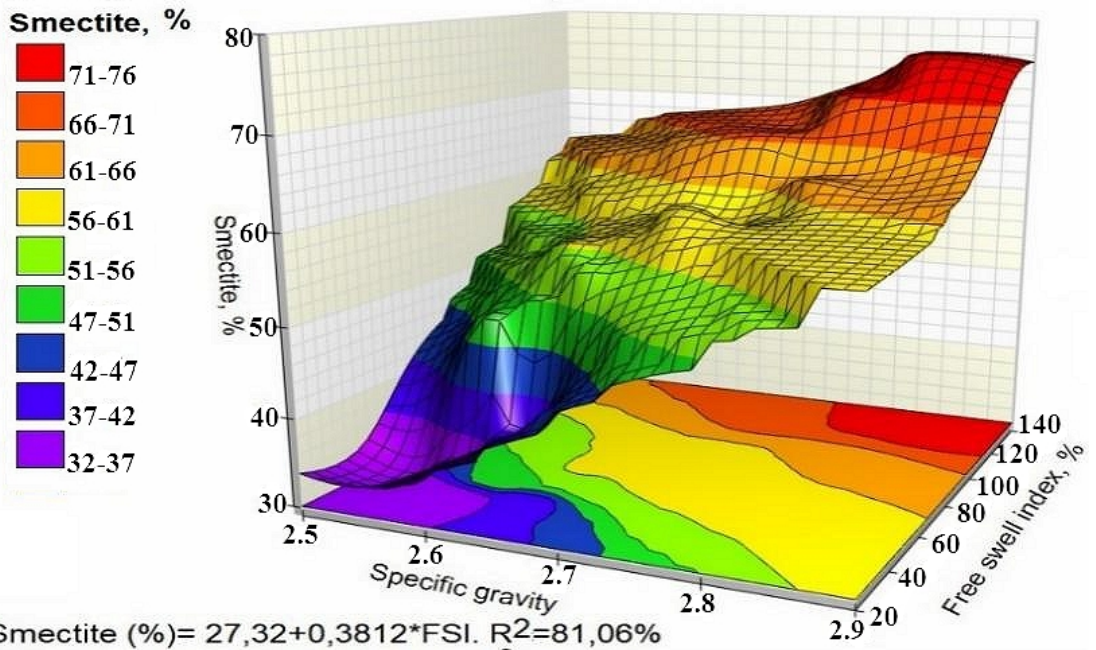

Smectite $(\%)=27,32+0,3812$ FI. $R 2=81,06 \%$ Smectite $(\%)=-327,9+147,7^{*}$ Gs. $R^{2}=81,06 \%$

Figure 3. Surface plot of smectite vs specific gravity. Free swell index 


\subsection{Analysis of the Correlation between Silica and Soil Properties}

The silica content response to the soil properties is presented in Table 5. The highlighted row exhibits the best subsets to correlate the silica content. Therefore, the analysis of the correlations between the silica content and plasticity index (PI), free swell ratio (FSR), Gravel (\%), and free swell index (FSI) is accomplished.

Table 5. Silica response

\begin{tabular}{|c|c|c|c|c|c|c|c|c|c|c|}
\hline Variables & R-Sq & R-Sq (adj) & R-Sq (pred) & Mallows Cp & PI, \% & FSR & Gravel, \% & FSI, $\%$ & Sand, $\%$ & Gs \\
\hline 1 & 43,1 & 38,7 & 27,9 & 75,7 & & & & & $\mathrm{x}$ & \\
\hline 1 & 28,8 & 23,4 & 8,8 & 97,1 & $\mathrm{x}$ & & & & & \\
\hline 2 & 74,2 & 69,9 & 63,3 & 30,2 & $\mathrm{x}$ & & $x$ & & & \\
\hline 2 & 72,3 & 67,7 & 59,1 & 33,1 & & & $\mathrm{x}$ & & $\mathrm{x}$ & \\
\hline 3 & 79,9 & 74,4 & 65,4 & 23,6 & $\mathrm{x}$ & & $\mathrm{x}$ & $\mathrm{x}$ & & \\
\hline 3 & 76,6 & 70,2 & 48,3 & 28,5 & & $\mathrm{x}$ & & $\mathrm{x}$ & $\mathrm{x}$ & \\
\hline 4 & 93,2 & 90,5 & 78,1 & 5,3 & $\mathrm{x}$ & $\mathrm{x}$ & $\mathrm{x}$ & $\mathrm{x}$ & & \\
\hline 4 & 91,4 & 88,0 & 75,6 & 8,0 & & $\mathrm{x}$ & & $\mathrm{x}$ & $\mathrm{x}$ & $\mathrm{x}$ \\
\hline 5 & 94,7 & 91,8 & 77,3 & 5,0 & $\mathrm{x}$ & $\mathrm{x}$ & $\mathrm{x}$ & $\mathrm{x}$ & $\mathrm{x}$ & \\
\hline 5 & 94,1 & 90,8 & 78,8 & 6,0 & $\mathrm{x}$ & $\mathrm{x}$ & $\mathrm{X}$ & $\mathrm{x}$ & & $\mathrm{x}$ \\
\hline 6 & 94,7 & 90,8 & 68,7 & 7,0 & $\mathrm{x}$ & $\mathrm{x}$ & $x$ & $\mathrm{x}$ & $x$ & $x$ \\
\hline
\end{tabular}
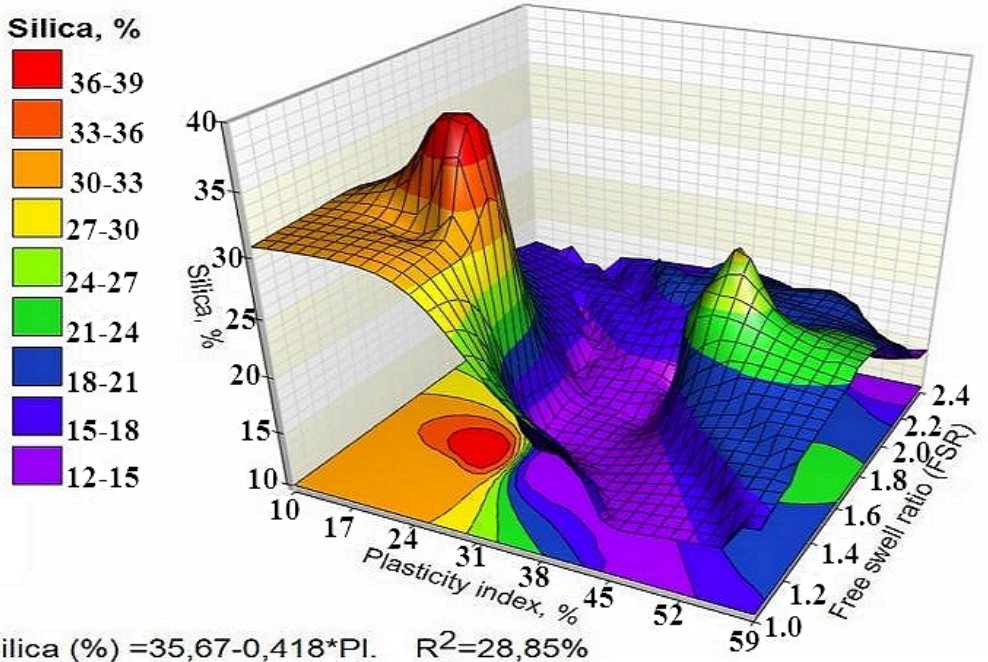

Silica $(\%)=35,67-0,418^{\star} \mathrm{PI} \quad \mathrm{R}^{2}=28,85 \%$

Silica $(\%)=38,50-10,38 * F S R \cdot R^{2}=21,82 \%$

Figure 4. Surface plot of silica vs plasticity index. Free swell ratio
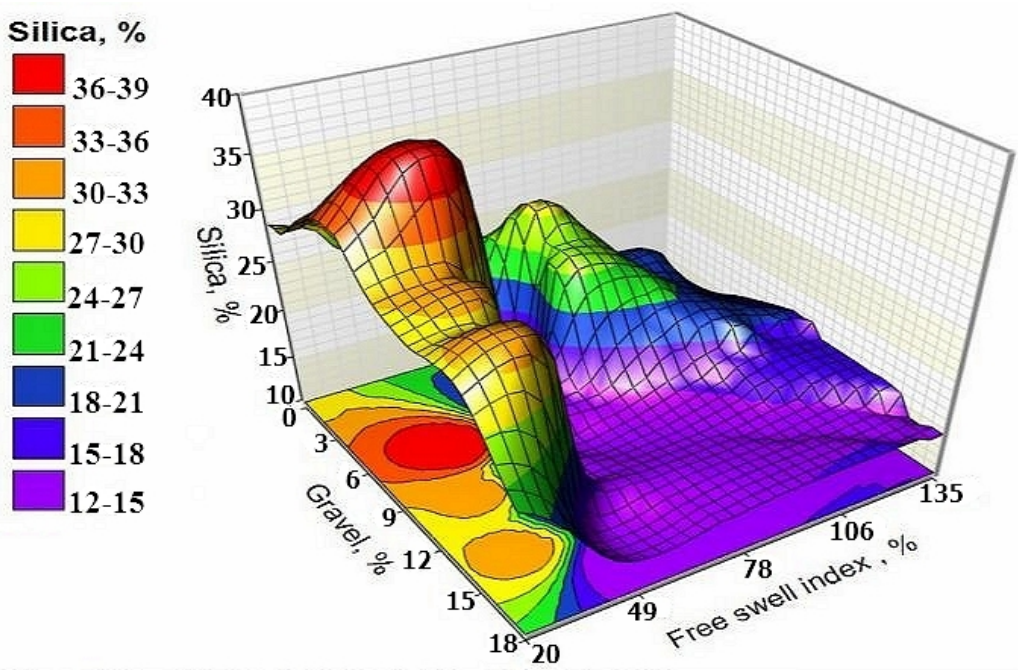

Silica $(\%)=28,21-0,1142 * F S I . R^{2}=21.82 \%$

[Silica $(\%)]^{-1}=0,00576+0.00028^{*}$ Gravel. $R^{2}=38 \%$

Figure 5. Surface plot of silica vs gravel. Free swell index 
Figures 4 \& 5 depict the three-dimensional representation of the relationship between the silica content and the following soil parameters: plasticity index, free swell ratio, gravel content, and free swell index. Colour patterns are used to represent the silica content values. Figure 4 shows a surface plot of silica, plasticity index, and free swell ratio. It can be observed a weak correlation between the silica content and the plasticity index, with a determination coefficient of $\mathrm{R}^{2}=28,85 \%$. The silica content decreases with the increase of the plasticity index. Furthermore, the silica content reduces with the augmentation of the free swell ratio and exhibits a weak correlation, with a determination coefficient of $\mathrm{R}^{2}=21,82 \%$. Figure 5 shows a surface plot of silica content, gravel content, and free swell index. It can be observed a reduction of silica content as the free swell index increases. The correlation between the silica content and the free swell index is weak, with a determination coefficient of $\mathrm{R}^{2}=21,82 \%$. Likewise, the silica content reduces with the increase of gravel content and displays a weak correlation, with a determination coefficient of $\mathrm{R}^{2}=38 \%$. The local extremes observed in the surface plot in Figures $4 \& 5$ are caused by some discrepancies between the correlations, with a determination coefficients of $\mathrm{R}^{2}<80 \%$. Conclusively, the correlation between silica content and these soil properties is weak. Nevertheless, the above-mentioned soil properties have a slight influence on silica content.

\subsection{Analysis of the Correlation Between k-feldspar and Soil Properties}

The k-feldspar content response to the soil properties are presented in Table 6 . The highlighted row displays the best subsets to correlate the k-feldspar content. Thus, the analysis of the correlations between the k-feldspar content and plasticity index (PI), free swell index (FSI), specific gravity (Gs), and free swell index (FSR) is performed.

Table 6. k-feldspar response

\begin{tabular}{|c|c|c|c|c|c|c|c|c|c|}
\hline Variables & R-Sq & $\begin{array}{l}\text { R-Sq } \\
\text { (adj) }\end{array}$ & $\begin{array}{c}\text { R-Sq } \\
\text { (pred) }\end{array}$ & $\begin{array}{c}\text { Mallows } \\
\text { Cp }\end{array}$ & PI, \% & FSI, \% & Gs & FSR & LL, \% \\
\hline 1 & 65,2 & 62,6 & 54,3 & 79,2 & & & $\mathrm{x}$ & & \\
\hline 1 & 60,4 & 57,3 & 51,1 & 91,8 & & $\mathrm{x}$ & & & \\
\hline 2 & 70,8 & 65,9 & 56,9 & 66,8 & & & $\mathrm{x}$ & & $\mathrm{x}$ \\
\hline 2 & 70,7 & 65,8 & 58,1 & 67,0 & & $\mathrm{x}$ & & $\mathrm{x}$ & \\
\hline 3 & 86,2 & 82,4 & 75,0 & 28,9 & $\mathrm{x}$ & $\mathrm{x}$ & $\mathrm{x}$ & & \\
\hline 3 & 82,8 & 78,2 & 72,9 & 37,5 & & $\mathrm{x}$ & $\mathrm{x}$ & $\mathrm{x}$ & \\
\hline 4 & 95,5 & 93,6 & 89,4 & 6,8 & $\mathrm{x}$ & $\mathrm{x}$ & $\mathrm{x}$ & $\mathrm{x}$ & \\
\hline 4 & 90,7 & 87,0 & 81,9 & 19,0 & $\mathrm{x}$ & $\mathrm{x}$ & & $\mathrm{x}$ & $\mathrm{x}$ \\
\hline 5 & 96,5 & 94,6 & 91,3 & 6,0 & $\mathrm{x}$ & $\mathrm{x}$ & $\mathrm{x}$ & $\mathrm{x}$ & $\mathrm{x}$ \\
\hline
\end{tabular}

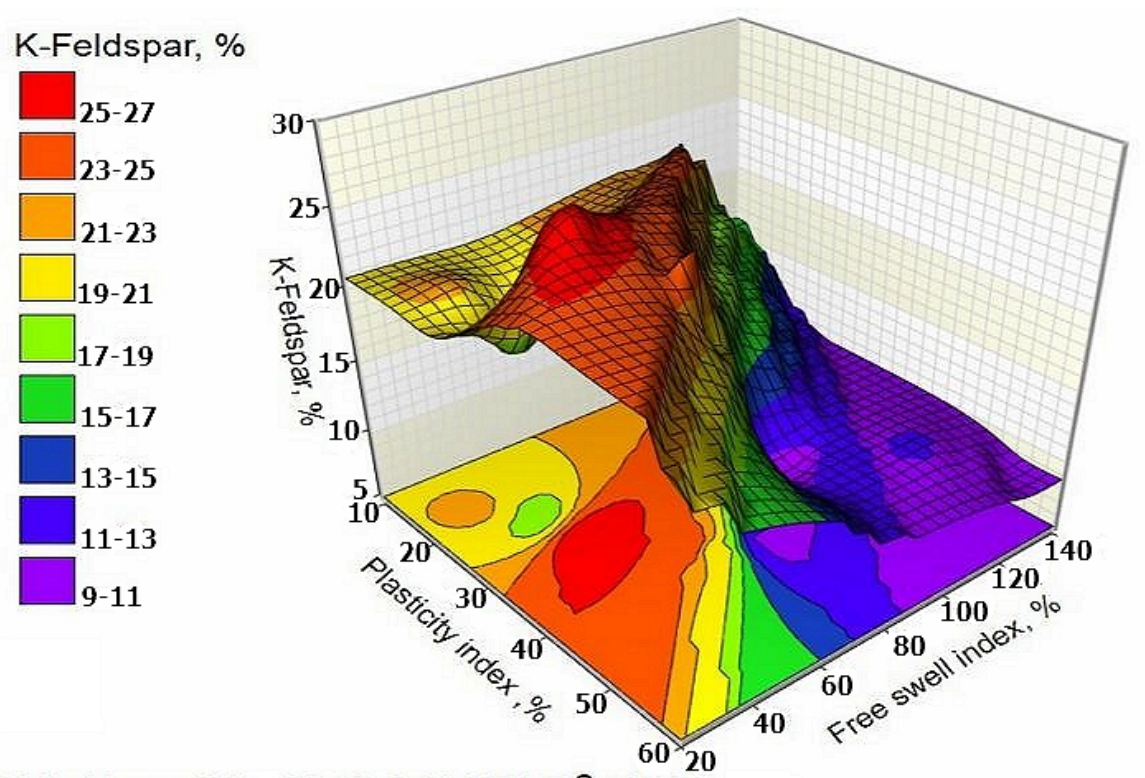

K-Feldspar $(\%)=33,18-0,411 * \mathrm{PI} . \mathrm{R}^{2}=47,2 \%$

K-Feldspar $(\%)=30,32-0,1723^{*}$ FSI. R ${ }^{2}=60,38 \%$

Figure 6. Surface plot of k-feldspar vs plasticity index. Free swell index 


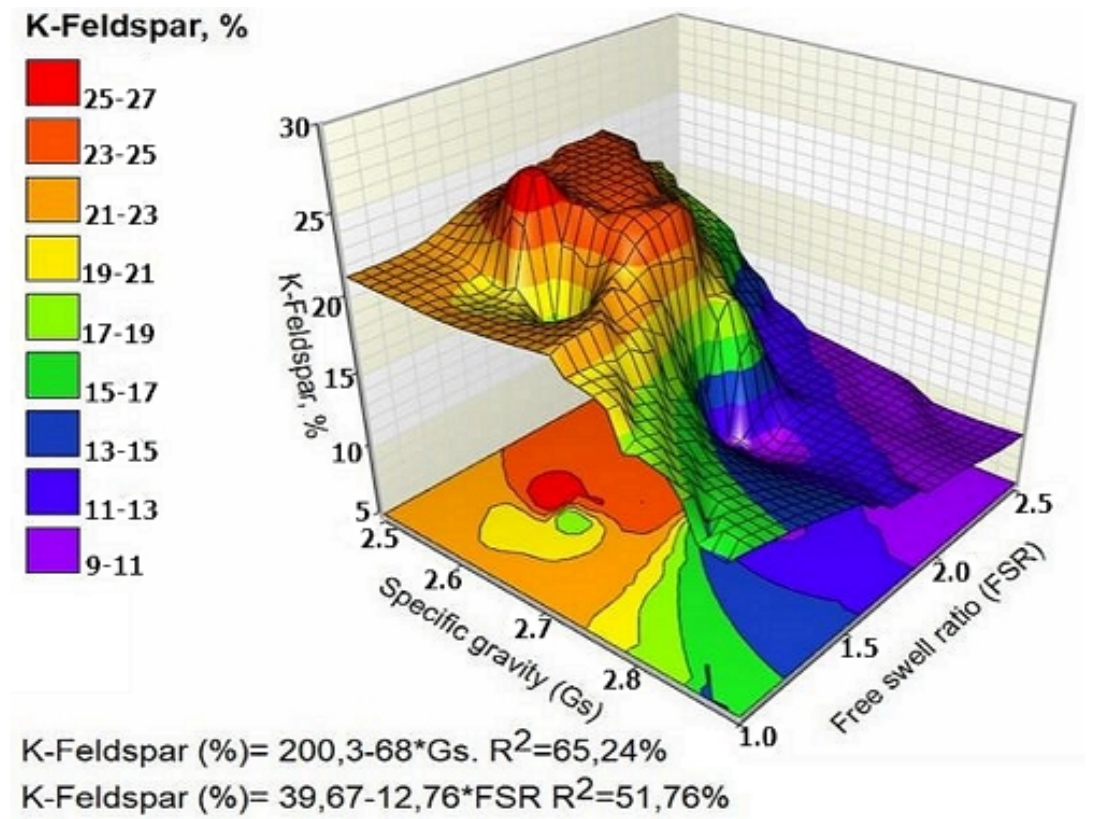

Figure 7. Surface plot of K-feldspar vs specific gravity. Free swell ratio

Table 7. Plagioclase response

\begin{tabular}{|c|c|c|c|c|c|c|c|c|c|}
\hline Variables & R-Sq & $\begin{array}{l}\text { R-Sq } \\
\text { (adj) }\end{array}$ & $\begin{array}{c}\text { R-Sq } \\
\text { (pred) }\end{array}$ & $\begin{array}{c}\text { Mallows } \\
\text { Cp } \\
\end{array}$ & LL, \% & LS, \% & FSI, \% & Gs & Clay, \% \\
\hline 1 & 92,7 & 92,2 & 90,4 & $-0,8$ & & $\mathrm{x}$ & & & \\
\hline 1 & 89,1 & 88,2 & 85,4 & 4,3 & $\mathrm{x}$ & & & & \\
\hline 2 & 93,2 & 92,1 & 90,5 & 0,5 & & $\mathrm{x}$ & $\mathrm{x}$ & & \\
\hline 2 & 92,8 & 91,6 & 89,6 & 1,1 & & $\mathrm{x}$ & & $\mathrm{x}$ & \\
\hline 3 & 93,3 & 91,5 & 89,7 & 2,3 & $\mathrm{x}$ & $\mathrm{x}$ & $\mathrm{x}$ & & \\
\hline 3 & 93,3 & 91,5 & 88,3 & 2,3 & & $\mathrm{x}$ & $\mathrm{x}$ & & $\mathrm{x}$ \\
\hline 4 & 93,6 & 91,0 & 89,0 & 4,0 & $\mathrm{x}$ & $\mathrm{x}$ & $\mathrm{x}$ & $\mathrm{x}$ & \\
\hline 4 & 93,4 & 90,8 & 86,9 & 4,2 & & $\mathrm{X}$ & $\mathrm{x}$ & $\mathrm{x}$ & $\mathrm{x}$ \\
\hline 5 & 93,6 & 90,0 & 85,3 & 6,0 & $\mathrm{x}$ & $\mathrm{x}$ & $\mathrm{x}$ & $\mathrm{x}$ & $\mathrm{x}$ \\
\hline
\end{tabular}

Figures $6 \quad \& \quad 7$ shows the three-dimensional representation of the correlation between the k-feldspar content and the soil parameters such as plasticity index, free swell index, specific gravity, free swell ratio. Colours patterns are used to represent $\mathrm{k}$-feldspar content values. Figure 6 exhibits a surface plot of the k-feldspar, plasticity index, and the free swell index. It can be observed a moderate correlation between the k-feldspar and free swell index, with a determination coefficient of $\mathrm{R}^{2}=60,38 \%$. The $\mathrm{k}$-feldspar content decreases when the free swell index increases. Also, k-feldspar content reduces with the increase of the plasticity index and exhibits a weak correlation, with a determination coefficient of $\mathrm{R}^{2}=47,2 \%$. Figure 7 represents a surface plot of k-feldspars, specific gravity, and free swell ratio. The k-feldspar content reduces as the specific gravity increases. There is a moderate correlation between the k-feldspar and the specific gravity, with a determination coefficient of $\mathrm{R}^{2}=65,24 \%$. Besides, $\mathrm{k}$-feldspar content reduces with the increment of free swell ratio and displays a moderate correlation with a determination coefficient of $\mathrm{R}^{2}=51,76 \%$. The local extremes observed in the surface plot in Figures $6 \& 7$ are induced by some discrepancies between the correlations, with a determination coefficients of $\mathrm{R}^{2}<80 \%$. Finally, the plasticity index, free swell index, specific gravity, and free swell ratio impact the k-feldspar content.

\subsection{Analysis of the Correlation between Plagioclase and Soil Properties}

Table 7 shows the plagioclase content response to soil properties. The highlighted row displays the best subsets to correlate the plagioclase content. Therefore, the analysis of the correlations between the plagioclase content and liquid limit (LL), Linear shrinkage (LS), free swell index (FSI), and specific gravity (Gs) is carried out. 


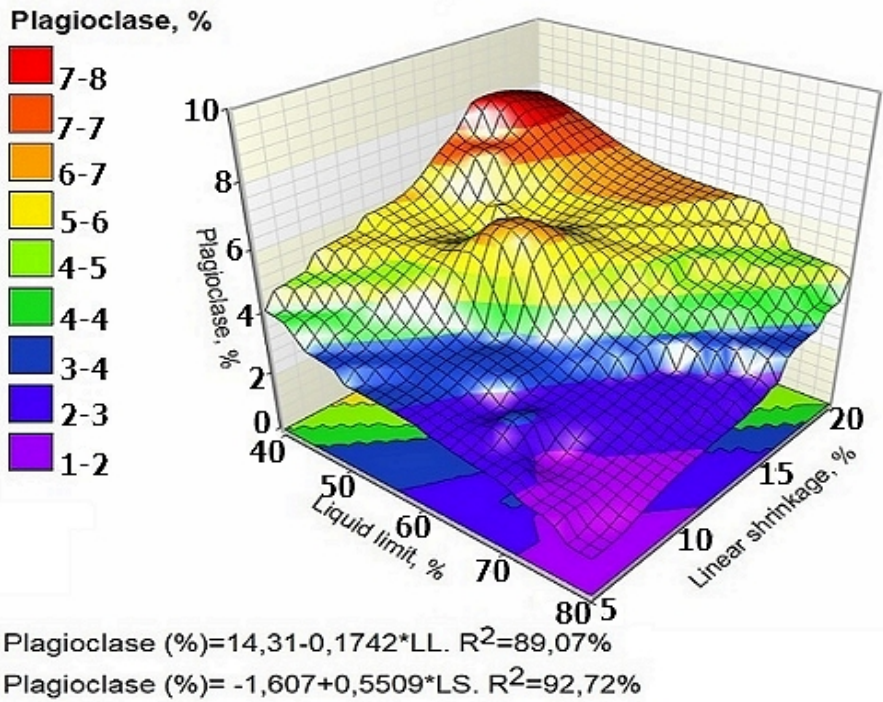

Figure 8. Surface plot of pagioclase vs liquid limit. Linear shrinkage

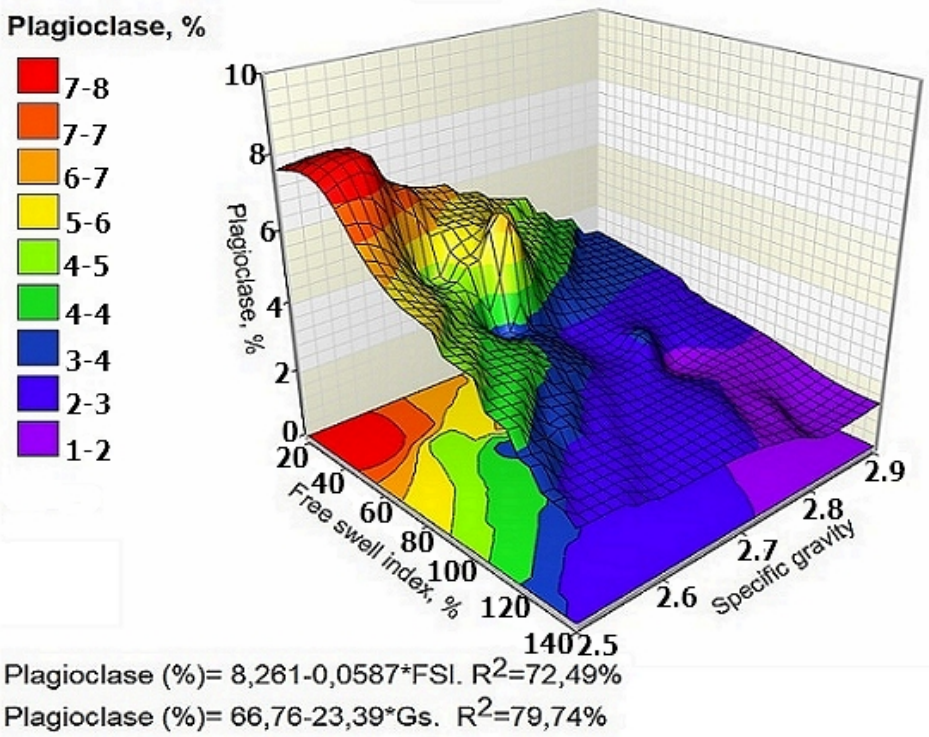

Figure 9. Surface plot of plagioclase vs free swell index. Specific gravity

Figures $8 \quad \& \quad 9$ portray the three-dimensional representation of the relationship between the plagioclase content and the soil properties: liquid limit, linear shrinkage, free swell index, and specific gravity. Colours patterns are utilized to indicate different values of plagioclase content. Figure 8 exhibits a surface plot of plagioclase content, liquid limit, and linear shrinkage. It can be noticed that there is a good correlation with small disparities between the plagioclase content and the liquid limit, with a determination coefficient of $\mathrm{R}^{2}=89,07 \%$. There is a tendency of decreasing of plagioclase content upon liquid limit increment. Besides, the plagioclase content decreases when the linear shrinkage increases and exhibits a good correlation with a determination coefficient of $\mathrm{R}^{2}=92,72 \%$. Figure 9 displays a surface plot of plagioclase content, free swell index, and specific gravity. The plagioclase content reduces upon the increment of the free swell index and portrays a moderate correlation, with a determination coefficient of $\mathrm{R}^{2}=72,49 \%$. Moreover, the plagioclase content reduces as the specific gravity increases and displays a moderate correlation, with a determination coefficient of $\mathrm{R}^{2}=79,74 \%$. The local extremes observed in the surface plot in Figure 9 are induced by some discrepancies between the correlations, with a determination coefficients of $\mathrm{R}^{2}<80 \%$. Lastly, the plagioclase content within the soil is influenced by the above-mentioned soil parameters.

\section{Models Development}

\subsection{Estimated Models}

Tables $1 \& 3$ are utilized as correlation matrices to 
perform multi-regression analysis using MINITAB 18 program. The model summary is shown in Table 8 . The mathematical prectictive model to evaluate the smectite content is described by Equation (2), and built up with the following independent variables: plasticity index, free swell ratio, specific gravity, and free swell index, with the respective correlation coefficients $\xi_{1}, \xi_{2}, \xi_{3}, \xi_{4}$ and the intercept $\xi_{0}$. The semi-empirical model to assess the silica content is given in Equation (3). This model is developed using the plasticity index, free swell ratio, gravel content, and free swell index, with the corresponding correlation coefficients $\eta_{1}, \eta_{2}, \eta_{3}, \eta_{4}$ and the intercept $\eta_{0}$. The predictive model to estimate the k-feldspar content stated in Equation (4) is developed utilizing the plasticity index, free swell ratio, specific gravity, and free swell index, with the respective correlation coefficients $\mu_{1}, \mu_{2}, \mu_{3}, \mu_{4}$ and the intercept $\mu_{0}$. Lastly, the semi-empirical model to quantify the plagioclase content is described by Equation (5) and developed using the liquid limit, linear shrinkage, free swell index, and specific gravity, with the corresponding correlation coefficients $\alpha_{1}, \alpha_{2}, \alpha_{3}, \alpha_{4}$ and the intercept $\alpha_{0}$.

Table 8. Models summary

\begin{tabular}{|c|c|c|c|c|c|}
\hline Models & $\mathrm{R}^{2}(\%)$ & Adjusted-R $^{2}(\%)$ & Predicted-R $^{2}(\%)$ & Intercepts & Correlation coefficients \\
\hline $\begin{array}{c}\text { Smectite } \\
(\%)\end{array}$ & 99,98 & 99,84 & 99,74 & $\xi_{0}=93,50$ & $\begin{array}{c}\xi_{1}=1,591 ; \xi_{2}=27,98 \\
\xi_{3}=42,99 ; \xi_{4}=0,425\end{array}$ \\
\hline $\begin{array}{c}\text { Silica } \\
(\%)\end{array}$ & 93,20 & 90,48 & 89,12 & $\eta_{0}=122,2$ & $\begin{array}{l}\eta_{1}=1,289 ; \eta_{2}=57,50 \\
\eta_{3}=1,930 ; \eta_{4}=0,806\end{array}$ \\
\hline $\begin{array}{c}\text { K-feldspar } \\
(\%)\end{array}$ & 95,46 & 93,65 & 89,35 & $\mu_{0}=302,8$ & $\begin{array}{c}\mu_{1}=0,976 ; \mu_{2}=36,84 \\
\mu_{3}=125,2 ; \mu_{4}=0,671\end{array}$ \\
\hline $\begin{array}{c}\text { Plagioclase } \\
(\%)\end{array}$ & 93,57 & 91,00 & 89,01 & $\alpha_{0}=11,1$ & $\begin{array}{l}\alpha_{1}=0,116 ; \alpha_{2}=0,464 \\
\alpha_{3}=0,0192 ; \alpha_{4}=5,89\end{array}$ \\
\hline
\end{tabular}

FSI $\geq 35 \%$ and FSR $\geq 1.10$

$$
\begin{gathered}
\text { Smectite }=+\xi_{0}+\xi_{1} \times \mathrm{PI}(\%)+\xi_{2} \times \mathrm{FSR}-\xi_{3} \times \mathrm{Gs}-\xi_{4} \times \mathrm{FSI}(\%) \\
\text { Silica }=+\eta_{0}-\eta_{1} \times \mathrm{PI}(\%)-\eta_{2} \times \mathrm{FSR}-\eta_{3} \times \mathrm{Gravel}(\%)+\eta_{4} \times \mathrm{FSI}(\%) \\
\mathrm{K}-\text { feldspar }=+\mu_{0}+\mu_{1} \times \mathrm{PI}(\%)+\mu_{2} \times \mathrm{FSR}-\mu_{3} \times \mathrm{Gs}-\mu_{4} \times \mathrm{FSI}(\%) \\
\text { Plagioclase }=-\alpha_{0}-\alpha_{1} \times \mathrm{LL}(\%)+\alpha_{2} \times \mathrm{LS}(\%)+\alpha_{3} \times \mathrm{FSI}(\%)+\alpha_{4} \times \mathrm{Gs}
\end{gathered}
$$

Where:

Smectite $=$ smectite content, $\%$,

Silica $=$ silica content, $\%$,

$\mathrm{K}-$ feldspar $=\mathrm{k}$-feldspar content, $\%$,

Plagioclase $=$ plagioclase content, $\%$,

$\mathrm{PI}=$ plasticity index, $\%$,

$\mathrm{LL}=$ liquid limit, $\%$,

FSI $=$ free swell index, \%,

$\mathrm{FSR}=$ free swell ratio,

$\mathrm{LS}=$ linear shrinkage, $\%$,

$\mathrm{Gs}=$ specific gravity

Gravel $(\%)=$ gravel content, \%,

$\mathrm{R}^{2}=$ determination coefficient, $\%$,

\begin{tabular}{|c|c|c|c|c|c|c|c|}
\hline \multicolumn{2}{|c|}{ Smectite } & \multicolumn{2}{|c|}{ Silica } & \multicolumn{2}{|c|}{ K-feldspar } & \multicolumn{2}{|c|}{ Plagiocalse } \\
\hline Term & P-value & Term & P-value & Term & P-value & Term & P-value \\
\hline $\mathrm{PI}, \%$ & 0,000 & PI,\% & 0,003 & $\mathrm{PI}, \%$ & 0,000 & LL, $\%$ & 0,004 \\
\hline FSR & 0,000 & FSR & 0,001 & FSR & 0,001 & LS, $\%$ & 0,014 \\
\hline Gs & 0,000 & Gravel,\% & 0,000 & Gs & 0,000 & Gs & 0,030 \\
\hline FSI,\% & 0,000 & FSI, $\%$ & 0,000 & FSI, $\%$ & 0,000 & FSI, \% & 0,034 \\
\hline
\end{tabular}

$\xi_{0}, \eta_{0}, \mu_{0}, \alpha_{0}=$ intercepts,

$\xi_{i}, \eta_{i}, \mu_{i}, \alpha_{i}=$ multi-regression coefficient, $i=1,2, \ldots . .4$.

Table 9. P-values for choosing the terms in prediction model 


\subsection{Models Validation}

The assessment of the models is conducted by evaluating the P-value of the term selected for each model, comparing the experimental values to the predicted values, and by analyzing the standardized residuals (errors) patterns. The primary criteria to select the relevant independent variable is the probability value (P-value). A hypothesis test is performed to determine the coefficient of each independent variable. When the P-value for the coefficient of the independent variable is higher than 0,05 , this coefficient is considered as zero, and the independent variable is viewed as insignificant and excluded from the model. The P-values of each model are shown in Table 9. It can be noticed that the P-values of the selected soil parameters are smaller than 0,05 . The comparison of the experimental values to the predicted values portrays a strong correlation with a scatter plot close to 1:1 and exhibits small disparities for all the models. Figure 10 illustrates the relationship between the experimental smectite content denoted by $\left(\mathrm{S}_{\mathrm{e}}\right)$ and the predicted smectite content denoted by $\left(\mathrm{S}_{\mathrm{P}}\right)$ with the trend line equation: $\mathrm{S}_{\mathrm{P}}(\%)=0,99 * \mathrm{~S}_{\mathrm{e}}(\%)$. Figure 11 exhibits the correlation between experimental silica content denoted by $\left(Q_{\mathrm{e}}\right)$ and predicted silica content denoted by $\left(Q_{P}\right)$ with the trend line equation $\mathrm{Q}_{\mathrm{P}}(\%)=0,93 * \mathrm{Q}_{\mathrm{e}}(\%)$. Figure 12 shows the relationship between experimental $\mathrm{k}$-feldspar content denoted by $\left(\mathrm{F}_{\mathrm{e}}\right)$ and predicted $\mathrm{k}$-feldspar content denoted by $\left(\mathrm{F}_{\mathrm{P}}\right)$ with the trend line equation: $\mathrm{F}_{\mathrm{P}}(\%)=0,95 * \mathrm{~F}_{\mathrm{e}}(\%)$. Figure 13 portrays the correlation between the experimental plagioclase content denoted by $\left(\mathrm{P}_{\mathrm{e}}\right)$ and the predicted plagioclase content denoted by $\left(\mathrm{P}_{\mathrm{P}}\right)$ with the trend line equation: $\mathrm{P}_{\mathrm{P}}(\%)=0,94 * \mathrm{P}_{\mathrm{e}}(\%)$.

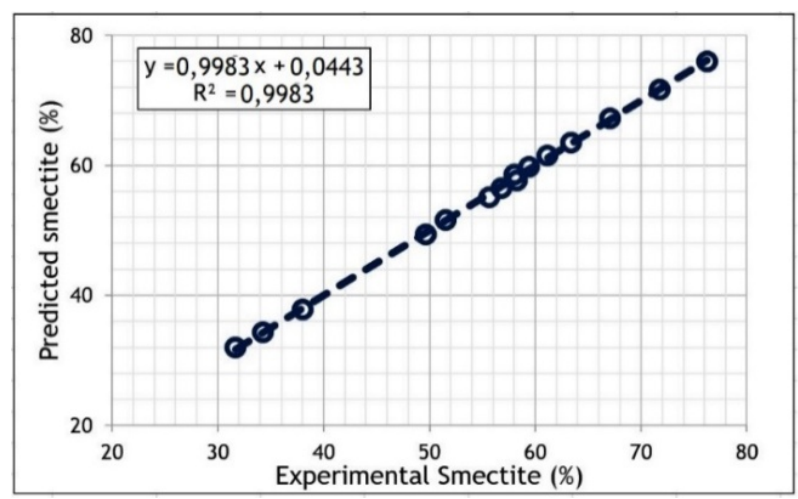

Figure 10. Predicted vs Experimental values (smectite, \%)

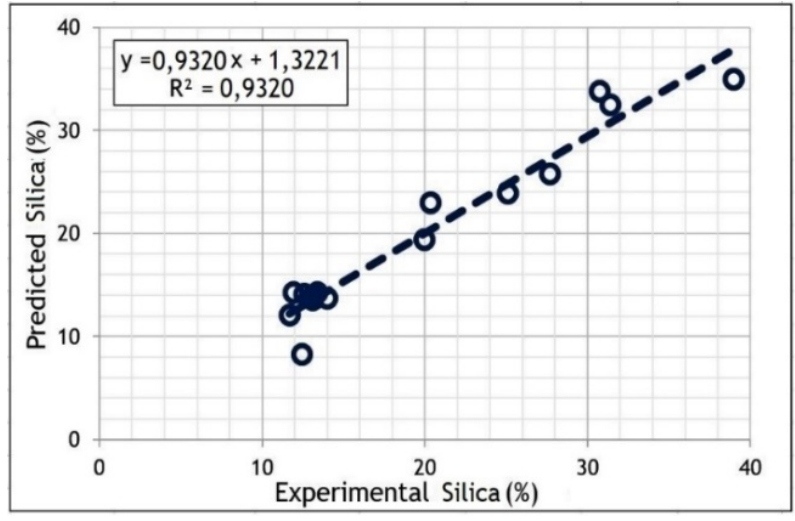

Figure 11. Predicted vs Experimental values (Silica, \%)

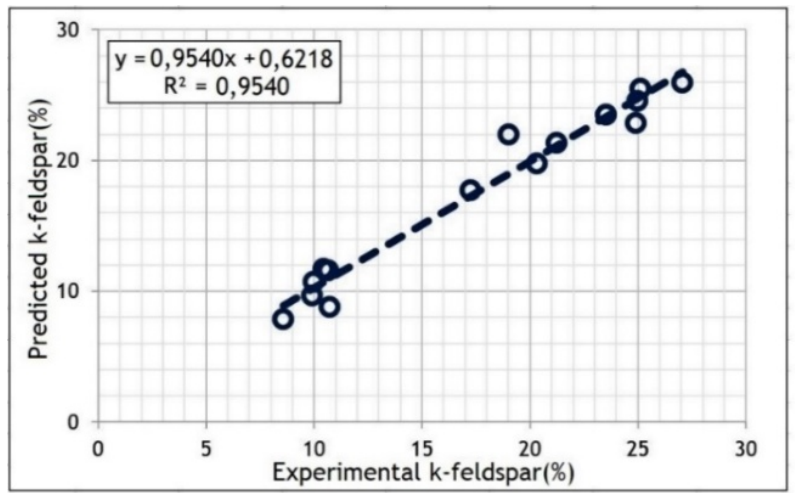

Figure 12. Predicted vs Experimental values (k-feldspar, \%)

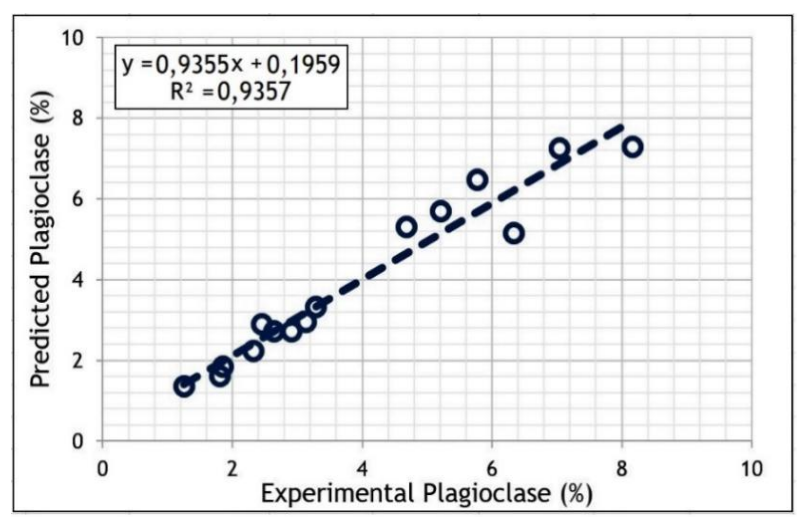

Figure 13. Predicted vs Experimental values (plagioclase, \%)

The investigation of residuals (errors) is significant in deciding on the accuracy of the model. If the residuals show any type of arrangement, the model isn't taking consideration for all the systematic data. For the best execution of the model, residuals have to be irregular. For example, they have to follow the typical distribution with zero mean and constant difference [14,15]. References [16] and [17] utilized $\left(\mathrm{R}^{2}\right)$ between experimental and predicted values for the assessment of model efficiency. All these approaches were additionally utilized by [18] for checking the model accuracy. The histograms of the residuals of smectite content and silica content are shown in Figures 14 \& 15 respectively. The residuals are distributed 
typically with zero mean and steady variance. The determination coefficients $\mathrm{R}^{2}$ for Equation (2) and Equation (3) are respectively $99,98 \%$ and $93,20 \%$. Furthermore, the histograms of the residuals of k-feldspar content and plagioclase content are shown in Figure 16 \& 17 respectively. The residuals are distributed typically with zero mean and steady variance. The determination coefficients $\mathrm{R}^{2}$ for Equation (4) and Equation (5) are respectively $95,46 \%$ and $93,57 \%$. These results are relevant in a statistical sense at $1 \%$ level of importance. Considering the adequacy of the proposed models, smectite content, silica content, k-feldspar content, and plagioclase content can be determined with acceptable accuracy.

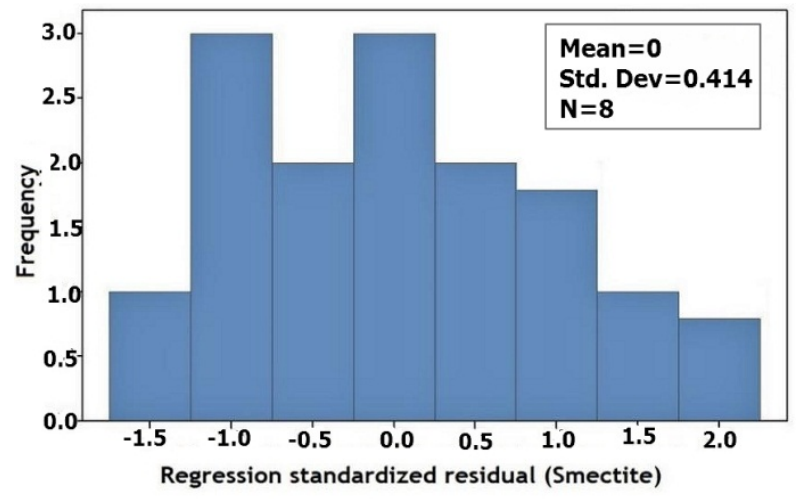

Figure 14. Standardized residual (smectite)

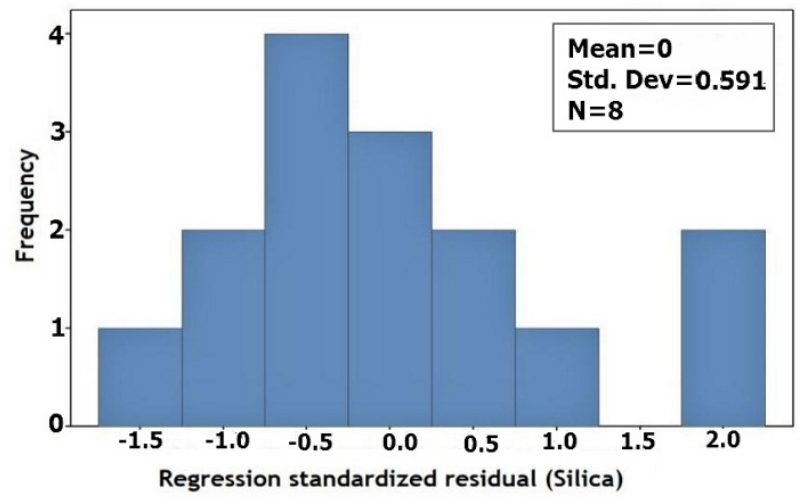

Figure 15. Standardized residual (Silica)

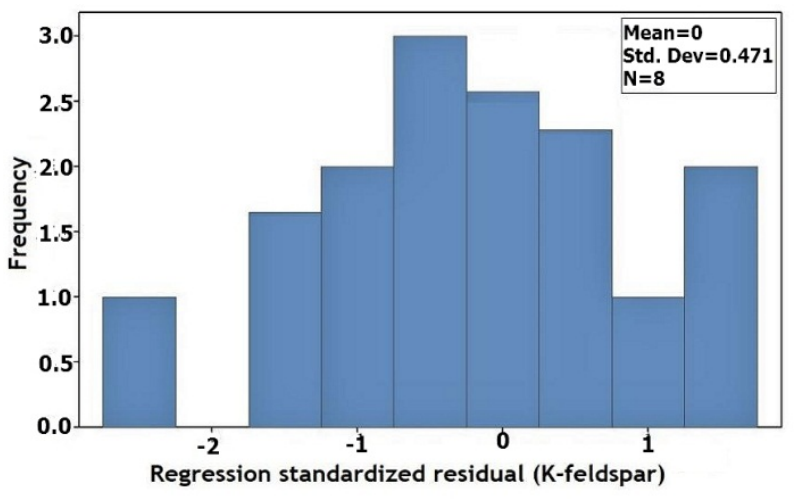

Figure 16. Standardized residual (k-feldspar)

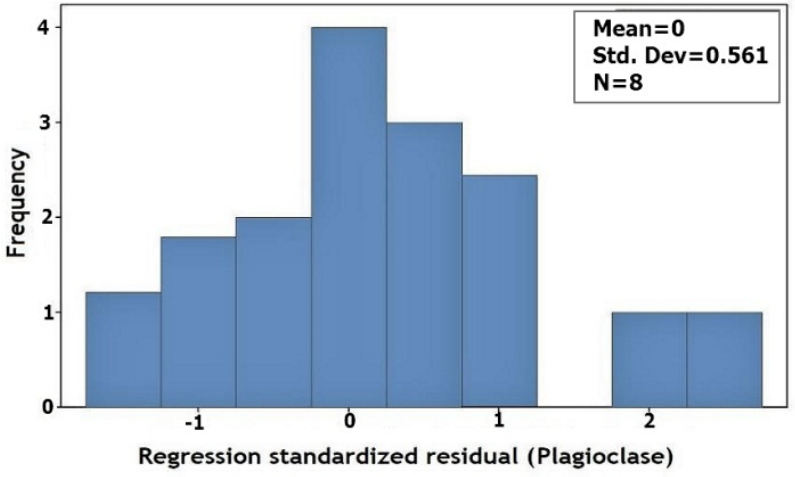

Figure 17. Standardized residual (plagioclase)

\section{Concluding Remarks}

The objective of this study is to develop mathematical predictive models to assess the mineral composition of heaving soils. To achieve that, the mineral composition, geotechnical index properties, and swelling properties are estimated. These soils portray a swelling behaviour. Moreover, smectite is the predominant clay mineral that influences the reactivity of these soils significantly. Besides, a small amount of illite is observed. Silica and feldspar group minerals (k-feldspar, plagioclase) are the predominant non-clay minerals. Also, a small amount of calcite is found. The mathematical predictive models engineered in this research work can be utilized as a tool for the preliminary assessment of the predominant minerals in heaving soils with acceptable accuracy. The time and the cost required for the X-ray diffraction test can be alleviated.

\section{Acknowledgment}

The authors thank the Central University of Technology (South Africa) for providing financial support of the research work presented in this article with grant number: GLA39134/4352.

\section{REFERENCES}

[1] Mitchell, JK, and K Soga. 1993. Fundamentals of Soil Behaviour. New York: John Wiley \& Sons p 422.

[2] Sridharan, A, and K Prakash. 2000. "Classification procedures for expansive soils." Proceedings of the Institution of Civil Engineers-Geotechnical Engineering 143: 235-240. Doi:10.1680/geng.2000.143.4.235.

[3] Oyediran, A, and HF Durojaiye.2011. "Variability in the geotechnical properties of some residual clay soils from south-western Nigeria." International Journal of Scientific \& Engineering Research 2(9):235-240. Doi: 10.14299/ijser. 2011. 09.001 
[4] Spagnoli, G, Sridharan A, Oreste P, Bellato D and L Di Matteo. 2018. "Statistical variability of the correlation plasticity index versus liquid limit for smectite and kaolinite." Applied Clay Science 156: 152-159. Doi: 10.1016/j.clay.2018.02.001.

[5] Akgün, H, Türkmenoğlu AG, Kelam AA, Yousefi-Bavil K, Öner G and MK Koçkar. 2018. "Assessment of the effect of mineralogy on the geotechnical parameters of clayey soils: A case study for the Orta County, Çankırı, Turkey. "Applied clay science 164: 44-53. Doi:10.1016/j.clay.2017.08.029.

[6] ASTM. 2009. Standard test method for particle-size distribution of soils using sieve analysis D 6913; 04. 09 (PA USA: American Society for Testing and Materials) Doi: 10.1520/d6913-04r09.

[7] ASTM. 2016. Standard test method for particle-size distribution (gradation) of fine-grained soils using the sedimentation sedimentationhydrometer) analysis, D 7928; 04. 09 (PA USA: American Society for Testing and Materials) Doi: 10.1520/d7928-16e01.

[8] ASTM .2005. Standard test method for liquid limit, plastic limit, and plasticity index of soils D 4318; 08 (PA USA: American Society for Testing and Materials) Doi: $10.1520 / \mathrm{d} 4318-17 \mathrm{e} 01$.

[9] BIS I .1977. Methods of test for soils: IS 2720-Part 40 Determination of free swell index of soils (New Delhi: Bureau of Indian standards).

[10] ASTM .2014. Standard test method for the specific gravity of soils D 854; 04. 08 (PA USA: American Society for Testing and Materials) Doi: 10.1520/d0854-14.
[11] Brindley, GW, and G Brown. 1984. Crystal Structures of Clay Minerals and their X-ray Diffraction Identification. London: Mineralogical Society.

[12] Johnson, RA, Miller I, and JE Freund. 2000. Probability and Statistics for Engineers. London: Pearson Education.

[13] Holtz, WG. 1954. "Engineering properties of expansive clays. " Transactions of the American Society of Civil Engineers 121: 641-677.

[14] Goyal, P, Chan AT, and N Jaiswal. 2006. Statistical models for the prediction of respirable suspended particulate matter in urban cities. Atmospheric Environment 40: 2068-2077 .Doi: 10.1016/j.atmosenv.2005.11.041.

[15] Montgomery, DC, Peck EA and GG Vining. 2003. Introduction to Linear Regression Analysis. New York: John Wiley \& Sons.

[16] Grivas, G, and A Chaloulakou. 2006. "Artificial neural network models for prediction of $\mathrm{PM}_{10}$ hourly concentrations, in the Greater area of Athens, Greece. " Atmospheric Environment. Electronic Materials 12: 1216 -1229. Doi:10.1016/j.atmosenv.2005.10.036.

[17] Papanastasiou, DK, Melas D, and I Kioutsioukis. 2007. " Development and assessment of neural network and multiple regression models in order to predict $\mathrm{PM}_{10}$ levels in a medium-sized Mediterranean city. "Water, air, \& soil pollution 182:325-334. Doi:10.1007/s11270- 007-9341-0.

[18] Roy, S, Adhikari GR, Renaldy TA, and AK Jha. 2011. "Development of multiple regression and neural network models for assessment of blasting dust at a large surface coal mine." Journal of Environmental Science and Technology 4:284-301. Doi: 10.3923/jest.2011.284.301. 